
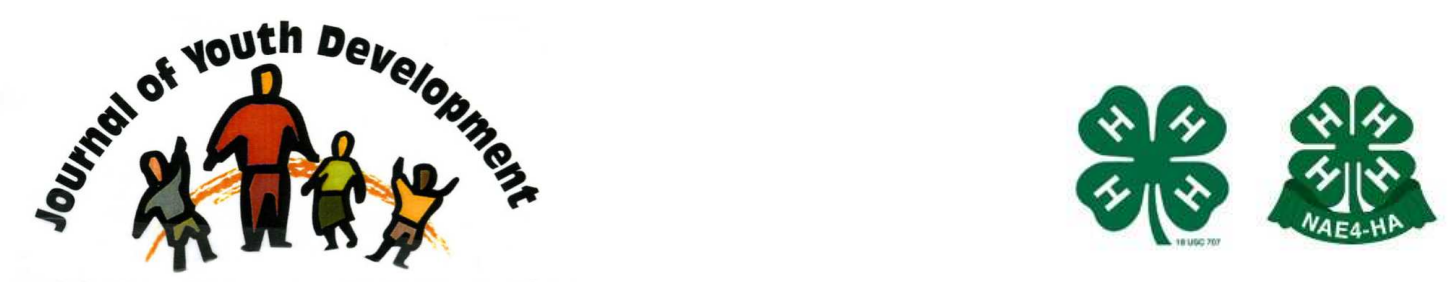

Bridging Research \& Practice

\title{
Adolescent Perceptions of Animation Violence as an Indication of Aggressive Attitudes and Behaviors
}

\author{
Rosemary V. Barnett \\ University of Florida \\ Gainesville, FL \\ rbarnet@ufl.edu \\ Joshua Hirsch \\ The Weiss School \\ Palm Beach Gardens, FL
}

Gerald R. Culen

University of Florida

Gainesville, FL

rbarnet@ufl.edu

Joy Jordan

University of Florida

Gainesville, FL

rbarnet@ufl.edu

Heather Gibson

University of Florida

Gainesville, FL

hgibson@hhp.ufl.edu 


\title{
JOURNAL OF YOUTH DEVELOPMENT \\ bridging research and practice

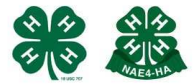

Volume 9, Number 1, Special Edition 2014

Article 140901FA008

\section{Adolescent Perceptions of Animation Violence as an Indication of Aggressive Attitudes and Behaviors}

\author{
Rosemary V. Barnett, Gerald R. Culen, Joy Jordan and Heather Gibson \\ University of Florida \\ Joshua Hirsch \\ The Weiss School
}

\begin{abstract}
This reported study was designed to examine the beliefs and perceptions of adolescents on whether or not viewing violence on television contributes to an increase in adolescents' abilities to learn aggressive attitudes and behaviors. It also explored the effects humor and satire used in the animated television series The Simpsons has on adolescents' abilities to learn aggressive attitudes and behaviors. Finally, it examined to what extent the violence portrayed in The Simpsons was believed to be realistic and justified by adolescents viewing the show. Results indicate that adolescents were not affected by the violence they observed in The Simpsons animation: Further, they did not feel that it was acceptable for their favorite characters to use violence to solve problems. Youth did not have reactions to viewing the series that were violent, nor did they report becoming aggressive in response to viewing the violence on the The Simpsons. While the majority of the youth also reported that they did not use violence to solve a problem, 3.3\% reported that they did. Overall, the study concluded that adolescents' exposure to violent content by viewing it in animation in The Simpsons did not affect adolescents' perceptions of their abilities to learn aggressive attitudes and behaviors. Youth did not perceive that the violence portrayed was realistic.
\end{abstract}

\section{Introduction}

Adolescence is often characterized as a time of challenge and turbulence (Roth \& Brooks-Gunn, 2000). This is a time in which adolescents experience many changes in their life. They undergo many physical, as well as psychological, changes with the onset of puberty and 
throughout this stage. Exposure to media has an impact on development that is not fully understood, yet is part of these changes that take place. On average, youth report watching TV for an average of 2 to 3 hours a day (Kaiser Family Foundation, 2010).

In 1950, however, only $10 \%$ of American homes had a television while today, a television can be found in $99 \%$ of homes (Nielson Media Research, 1995). Television interferes with the development of intelligence, thinking skills and imagination (Kinderstart, 2000). A crucial element of thinking is being able to extrapolate from what you know and determine how it applies in a new situation. School requires this method of thinking, while television does not. Habitual television viewing denies opportunities for adolescents' imagination to develop (Kinderstart, 2000).

Television violence is "Any overt depiction of the use of physical force or credible threat of physical force intended to physically harm an animate being or group of beings. Violence also includes certain depictions of physically harmful consequences against an animate being or group that occur as a result of unseen violent means" (National Television Violence Study, Executive Summary, 1996). Possibly one of the most influential factors on adolescent violence is violent content in the media (Mental Health, 2004), yet research is still being conducted to investigate its real effect. Aggression is defined as behavior designed to harm or injure another person. Violence is the exertion of physical force so as to injure or abuse (Dictionary.com, 2005). Violence is a more serious form of aggression that causes serious harm.

Children and adolescents are influenced and affected by media that they observe and interests them. As they develop, they learn by observing, imitating, and making these observed behaviors their own. Adolescents learn aggressive attitudes and behaviors by imitating observed models of violence and aggression (DuRant, Treiber, Goodman, \& Woods, 1996). Repeated exposure to violent content in the media can, therefore, lead to increased feelings of hostility, expectations that others will behave aggressively, desensitization to the pain of others, and increased likelihood of interacting and responding to others with violence (Rich, 2000).

When children and adolescents are exposed to violent content in the media, they have a greater chance of exhibiting violent and aggressive behavior later in life, than children who have not been exposed to violent content in the media (Congressional Public Health Summit, 2000). Despite the substantial body of knowledge on the general link between television and violence, there is a lack of research on the effects of violence in humorous situations on television programming. In order to better understand the effects of cartoon violence on youth, there is a need for more studies (Hapkiewicz, 1979; Wilson, Smith, Potter, Kunkel, Linz, Colvin, \& Donnerstein, 2002). The highest proportion of violence in television has been found in children's shows (Wilson, et al., 2002). Roughly seven out of ten children's shows contained some violence, as opposed to non-children's shows containing six out of ten incidents (Wilson, et al., 2002).

Seven contextual features of violence were identified that affect the likelihood that a viewer will learn aggressive attitudes and behaviors from a portrayal (Wilson, Kunkel, Linz, Potter, Donnerstein, Smith, Blumenthal, \& Gray, 1997). The first contextual feature of violence is that an attractive perpetrator, or good-looking character, increases the risk of learning aggression. According to Bandura's (1994) social learning theory, children as well as adults are more likely to attend to, identify with, and learn from attractive role models than unattractive ones. 
Motive or reason for violence is the second contextual feature. Violent actions that seem justified or morally defensible can facilitate viewer aggression, whereas unjustified violence can actually diminish the risk of learning aggression (Geen, 1981). When a character has a good reason to justify the use of violence, it can lead to the learning of aggressive behaviors. The third feature of violence is the presence of weapons in a portrayal and conventional weapons such as guns and knives can enhance aggressive responding among viewers. Weapons are assumed to function as a violent cue that can prime aggressive thoughts in a viewer (Berkowitz, 1990).

Violence that seems realistic can promote the learning of aggressive attitudes and behaviors among viewers (Atkin, 1983). An example of this fourth feature of violence would be a brother trying to defend his sister from bullies by using karate moves to beat them up. An adolescent can associate the use of violence as an appropriate means to solve a problem and justify their behavior accordingly. The fifth feature refers to Bandura's (1965) social learning theory and how violence that is explicitly rewarded or that simply goes unpunished increases the risk of imitative aggression, whereas violence that is condemned decreases the risk. The viewing by an adolescent of a perpetrator on television committing a violent act and not getting caught and/or punished can lead to the justification by the adolescent of committing violent acts themselves, since the perpetrator was not punished.

Consequences of violence for the victim are an important contextual cue; the sixth feature of violence displays explicit portrayals of a victim's physical injury and pain and can actually decrease or inhibit the learning of aggression among viewers (Wotring \& Greenberg, 1973). For example, the cartoon Itchy \& Scratchy seen on The Simpsons is a horrific cartoon depicting a cat (Scratchy) and mouse (Itchy) continually attacking and mutilating each other with a variety of deadly weapons. Both Itchy and Scratchy are fine by the next episode, no matter how mutilated they were in the previous episode. Since the actual consequences of the injuries sustained by both Itchy and Scratchy are not portrayed, this can lead to the learning of aggressive behaviors.

Violence that is portrayed as humorous can increase aggression in viewers (Baron, 1978). This is the final feature of violence. Humor has the ability to trivialize the seriousness of violence (Gunter, \& Furnham, 1984) and that humor also may serve as a positive reinforcement or reward for violence (Berkowitz, 1970). The study of humor's association with violence has continued over the years. When violent scenes involve humor either directed at the violence or used by characters involved with the violence, positive values can be assigned to viewing acts of violence and lead to acceptance of these (U.S. Department of Health and Human Services, 2001).

Through prolonged use of the media, adolescents can become desensitized to the point where they lose their ability to empathize with both the victim and the aggressor. One study found that both children and adults were less physiologically aroused by a scene of real-life aggression if they had previously watched a violent drama on television than if they had watched a nonviolent program (Thomas, Horton, Lippincott, \& Drabman, 1977). Thomas and Drabman (1975) exposed first and third graders to either a violent or a nonviolent television program. After viewing the programs, they were placed in charge of monitoring the behavior of two preschoolers at play. Older children who had seen the violent television program were significantly slower in seeking help when the preschoolers broke into a fight than were those who had seen the nonviolent show (Thomas, \& Drabman, 1975). 
This study explored the effects that violent television content has on adolescents' beliefs and perceptions. It also examines the effects humor and satire used on the animated television series The Simpson's has on adolescent abilities to learn aggressive attitudes and behaviors. The first objective was to determine whether viewing violence on television contributes to an increase in adolescents' abilities to learn aggressive attitudes and behaviors. The second objective explored the effects that humor and satire used on the animated television series The Simpsons have on adolescents' abilities to learn aggressive attitudes and behaviors. The final objective explored to what extent the violence portrayed in the show is believed to be realistic and justified by adolescents viewing the show. Several key factors contribute to, or predict, desensitization to violence and the learning of aggressive behavior.

\section{Methods}

\section{Sample and Procedures}

The population was adolescents who were in Florida in $4-\mathrm{H}$, ages $13-17$, attending the State 4- $\mathrm{H}$ Congress at the University of Florida. 4- $\mathrm{H}$ is the youth education branch of the Cooperative Extension Service, a program of the United States Department of Agriculture (National 4-H Web, 2005). The sample group of 245 individuals were those youth who elected to participate after the purpose of the study was introduced and explained. The study was conducted in the dormitories at a large southeastern university where participants were housed for 4-H Congress. The participants were briefed on the topic, benefits/risks, expected length of completion, and who to contact with questions or concerns. Prior to attending, blanket consent forms were sent to participants' homes in informational packets. Confidentiality was ensured through the anonymous format of the survey, which was handed in face down when completed. Identification numbers were later assigned for data analysis after the surveys had been randomly mixed.

\section{Research Design and Instrumentation}

This cross-sectional study observed a defined population at a single point in time. The unit of analysis, or the major entity was the individual (Social Research Methods, 2002). Recruitment of subjects was on a voluntary basis. Potential participants were given the option of whether they would like to be informed of the results of the study. The survey instrument measured exposure and outcome simultaneously (Bandolier, 2005).

This study included an examination of the perceived effects of one television show containing animated violence. The show selected for this study was The Simpsons because it frames violence with humor and satire and contains imbedded violence. The animated violence in The Simpsons is often portrayed in a humorous manner. Satire is defined as trenchant wit, irony, or sarcasm used to expose and discredit vice or folly (Dictionary.com, 2005). The Simpsons uses satire, in relation to violence, as a means to both convey a message and evoke thought.

The Simpsons are your typical nuclear family living in Springfield, USA. Homer is a father who gives bad advice and works as the safety inspector at the Springfield Nuclear Power Plant; Marge is a loving, nurturing mother and wife who tries to keep peace in the family; Bart is a rambunctious 10-year-old; Lisa is a smart, philosophical 8-year-old, who loves to play the saxophone; and Maggie is the baby, who communicates by sucking her pacifier (Simpson Crazy, 2001). The cartoon is filled with political satire and topical commentary, written by Harvard and Yale graduates, marketed towards youth, and enjoyed by adults. Over the 16 seasons in the town of Springfield, USA The Simpsons have not aged a day. It is this agelessness that allows for The Simpsons to be enjoyed by fans of any age (Simpson Crazy, 2001). 
The survey instrument consisted of eighty-four items and was comprised of a general information section and four content sections using the Likert scalar response style and fill-in questions. The four content sections were: Television Viewing, Beliefs and Perceptions, Cartoon Viewing, and The Simpsons. The instrument was pilot-tested by a group of four local high school students. A second revision of the instrument was pilot tested by four local high school students and a team of adolescent experts. A scale considered to have good internal consistency has a Cronbach alpha coefficient reported of 0.85 . In the current study the Cronbach alpha coefficient was 0.825 . This scale can be considered to have good internal consistency for use in future studies. The instrument focused on the seven contextual features of violence and adolescents' beliefs and perceptions. Analyses of the results of these items were useful in determining adolescents' beliefs and perceptions and their relationship to aggressive attitudes and behaviors. Items were scored on a one, Strongly Disagree, to five, Strongly Agree, Likert scale. In those instances where reverse coding was needed, it was done prior to data analysis.

In order to investigate the primary research questions about adolescents' beliefs and perceptions and aggressive behavior and attitudes through exposure to violence by viewing it on television/cartoons/ The Simpsons, chi-square analysis, along with Kendall's Tau-b, was conducted. All of these statistical analyses were completed utilizing SPSS. In order to examine adolescents' perceptions of violence portrayed on television and in The Simpsons and what effects it had on their unrealistic views of violence in the real world chi-square analysis was conducted. Chi-square analysis, along with Kendall's Tau-b, was conducted to examine the next secondary research question, which addressed adolescents' perceptions of the justification of violence portrayed in The Simpsons. All of these statistical analyses were completed utilizing SPSS.

\section{Results}

\section{The Sample}

Girls made up more than three-fourths of the sample (82.2\%), or 199 of the 245 participants, and boys composed less than a fourth of the sample (17.8\%), or 43 of the 245 participants. Due to data collection occurring at the State 4-H Congress, a majority-female gender breakdown was expected, however, the higher than expected female response rate is also accounted for by an overall higher willingness by females to participate in the study, as an approximately equal opportunity for all youth participants was made available. The ages of participants in the study ranged from thirteen years old to nineteen years old, with the bulk of participants between the ages of fifteen and sixteen years old. All of the study participants were members of $4-\mathrm{H}$ and attended either public school $(55.9 \%)$, private school $(8.2 \%)$ or were home schooled (33.1\%).

\section{Television Viewing}

The first content section examined television-viewing habits of the participants and the relative importance placed upon television in the home. The first question, used as a screening question, asked participants whether or not they watch television of the participants, 218 of the $239(91.2 \%)$ reported that they watch television while $21(8.8 \%)$ answered that they do not watch television. When asked for their approximate amount of television viewing each day, the highest frequency hours of television watched in an average day was two, reported by 49 out of the $206(23.8 \%)$ participants. The second highest frequency of television watched, reported by 41 out of the 206 (19.9\%) participants was one hour, followed by three hours a day, reported 
by 29 out of the 245 (14.1\%) participants. Twenty out of the $206(9.7 \%)$ participants answered they watched four hours of television on an average day and 18 out of the 206 $(8.7 \%)$ participants answered they watched five hours of television on an average day. When participants were asked if they have a television in their bedroom, 50\% reported that they did and $50 \%$ reported that they did not have a television in their bedroom.

When the 217 participants were asked whether their favorite type of television program is funny, a little more than one-third of participants, $81(37.3 \%)$ strongly agreed, more than onefourth of participants, 60 (27.6\%) were neutral, 57 (26.3\%) participants agreed, $11(5.1 \%)$ participants disagreed, and eight out of 217 (3.7\%) strongly disagreed. Participants were also asked if they believed their favorite type of television program is violent. The majority of participants either strongly disagreed or disagreed, 66 out of $214(30.8 \%)$ and 61 out of 214 (28.5\%) respectively, while 44 out of $214(20.6 \%)$ participants were neutral, 32 out of 214 (15\%) participants agreed, and 11 out of 214 (5.1\%) participants strongly agreed. Analyses of the results helped in determining participants' beliefs and perceptions on the consequences of television violence.

\section{Cartoon Viewing}

As a screening question, participants were asked whether or not they watch cartoons. If they answered "No" to this question, they were instructed to go to a general group of questions and were not asked the questions about cartoon violence in The Simpsons. Of the 214-person sample, 108 (50.5\%) participants watched cartoons and 106 (49.5\%) participants did not watch cartoons.

\section{The Simpsons}

Participants who watched cartoons were next examined for their viewing habits and perceptions of The Simpsons. It also asked participants about their beliefs and perceptions about Itchy and Scratchy, a cartoon show the Simpsons family watches often on television. As in the Television and Cartoon Viewing sections, the first question was used for screening. Of this sample, 73 out of 116 (62.9\%) participants reported that they watched The Simpsons and 43 out of 116 (37.1\%) participants did not watch The Simpsons. Another item in this section asked participants about their approximate amount of hours of The Simpsons they view in an average week. The highest frequency hours of The Simpsons watched in an average week was one, with 19 out of $68(27.9 \%)$ participants. The second highest frequency hours of The Simpsons watched in an average week was one-half, with 11 out of the $68(16.2 \%)$ participants, followed by three hours a week, with nine out of the $68(13.2 \%)$ participants. Six out of the $68(8.8 \%)$ participants answered they watched two hours of The Simpsons in an average week and two out of $68(2.9 \%)$ participants answered they watched five hours of The Simpsons in an average week.

\section{Statistical Analysis of Research Questions}

\section{Relationship Between Beliefs \& Perceptions and Exposure to Television Violence To what extent are adolescents' beliefs and perceptions affected regarding the learning of aggressive attitudes and behaviors through exposure to violence by viewing it on television? The purpose of this question was to determine if there is a relationship between participants' beliefs and perceptions and exposure to television violence.}

Conducting chi-square analysis on the dependent variable The older one gets, the more used to they are seeing violence on television and two independent variables indicated the presence of 
some significant relationships. A significant relationship was found between the independent variable, which states After watching violence on television, it bothers me, and the dependent variable $(n=214)$. About one-third of the participants, (70), Strongly Agreed/Agreed with the item After watching violence on television, it bothers me $(32.71 \%)$; close to one-third of participants, (71), were Neutral about this item (33.18\%); and 73 participants Strongly Disagreed/Disagreed (34.11\%). Kendall's tau-b was determined to have a value of -0.207 with a $\mathrm{p} \geq 0.000$. This indicates there was a statistical correlation with the dependent variable The older one gets, the more used to they are seeing violence on television. Participants who Strongly Disagree/Disagree with this item will have linear concordance in their answers in relation to the dependent variable. Since the value for Kendall's tau-b was relatively low, -.207 , the relationship between the dependent variable and this item was weak.

The chi-square value for this item was 34.087 with a $p \geq$ of 0.005 and 16 DF. The chi-square value at the $95^{\text {th }}$ percentile with 16 DF was 26.30. Since the computed chi-square value was greater than the chi-square value in the table of distribution, the research hypothesis, adolescents' exposure to violent content by viewing it on television has effects on the beliefs and perceptions of adolescents' abilities to learn aggressive attitudes and behaviors, was rejected.

The final independent variable determined to be of significance by conducting chi-square analysis was After watching violence on television, it makes me angry $(\mathrm{n}=209)$. (See Table 1$)$ Close to half of the participants (100) Strongly Disagreed/Disagreed with the item After watching violence on television, it makes me angry (47.85\%); 80 participants were Neutral about this item (38.28\%); and 29 participants Strongly Agreed/Agreed (13.88\%). Kendall's tau- $b$ was determined to have $a$ value of -0.188 with $a p \geq 0.001$. This indicates there was $a$ statistical correlation with the dependent variable The older one gets, the more used to they are seeing violence on television. Participants who Strongly Disagree/Disagree with this item will have linear concordance in their answers in relation to the dependent variable. Since the value for Kendall's tau-b was relatively low, -0.188 , the relationship between the dependent variable and this item was weak.

\section{Table 1}

Comparison of the older I get, the more I get used to seeing violence on television and after watching violence on television, it makes me angry Cross tabulation.

\begin{tabular}{|l|l|l|l|l|l|l|}
\hline \multirow{5}{*}{} & \multicolumn{7}{|c|}{ TV Angry } \\
\cline { 2 - 7 } & & $\begin{array}{l}\text { Strongly } \\
\text { Disagree }\end{array}$ & Disagree & Neutral & Agree & $\begin{array}{l}\text { Strongly } \\
\text { Agree }\end{array}$ \\
\cline { 2 - 7 } & $\begin{array}{l}\text { Strongly } \\
\text { Disagree }\end{array}$ & $.48 \%$ & $1.44 \%$ & $1.91 \%$ & $0 \%$ & $.48 \%$ \\
\cline { 2 - 7 } & Disagree & $.97 \%$ & $.97 \%$ & $4.78 \%$ & $.48 \%$ & $.48 \%$ \\
\cline { 2 - 7 } & Neutral & $3.83 \%$ & $6.69 \%$ & $7.18 \%$ & $1.91 \%$ & $1 / 44 \%$ \\
\cline { 2 - 7 } & Agree & $8.1 \%$ & $10.01 \%$ & $20.1 \%$ & $6.22 \%$ & $1.91 \%$ \\
\cline { 2 - 7 } & $\begin{array}{l}\text { Strongly } \\
\text { Agree }\end{array}$ & $10.05 \%$ & $5.26 \%$ & $4.31 \%$ & $.48 \%$ & $.48 \%$ \\
\hline
\end{tabular}

Note: $\chi 2=31.445$ DF $=16 p>.012$ Kendal's tau- $b=.188 p>.001$

The chi-square value for this item was 31.445 with a $p \geq 0.012$ and 16 DF. The chi-square value at the $95^{\text {th }}$ percentile with 16 DF was 26.30. Since the computed chi-square value was greater than the chi-square value in the table of distribution, the research hypothesis, 
adolescents' exposure to violent content by viewing it on television has effects on the beliefs and perceptions of adolescents' abilities to learn aggressive attitudes and behaviors, was rejected.

\section{Relationship Between Beliefs \& Perceptions and Exposure to Animated Violence} To what extent are adolescents' beliefs and perceptions affected regarding the learning of aggressive attitudes and behaviors through exposure to violence in animation on television? The purpose of this question was to determine if there is a relationship between participants' beliefs and perceptions and exposure to animated violence. Conducting chi-square analysis on the dependent variable The older one gets, the more used to they are seeing violence in cartoons and two independent variables indicated the presence of some significant relationships.

The first independent variable indicating a significant relationship with the dependent variable was My favorite type of television program is funny $(n=212)$ About two-thirds of the participants (135) Strongly Agreed/Agreed with the item My favorite type of television program is funny (63.68\%); more than one-fourth of the participants, 59, were Neutral about this item (27.83\%); and 18 participants Strongly Disagreed/Disagreed (8.49\%). Kendall's tau-b was determined to have a value of 0.180 with a $p \geq 0.002$. This indicates there was a statistical correlation with the dependent variable The older one gets, the more used to they are seeing violence in cartoons. Participants who Strongly Agree/Agree with this item have linear concordance in their answers with relation to the dependent variable. Since the value for Kendall's tau-b was relatively low, 0.180 , the relationship between the dependent variable and this item was weak.

The chi-square value for this item was 45.383 with a $p \geq 0.000$ and 16 DF. The chi-square value at the $95^{\text {th }}$ percentile with 16 DF was 26.30. Since the computed chi-square value was greater than the chi-square value in the table of distribution, the research hypothesis, adolescents' exposure to violent content by viewing it in animation had effects on the beliefs and perceptions of adolescents' abilities to learn aggressive attitudes and behaviors, was rejected.

The final independent variable indicating a significant relationship with the dependent variable was Violence goes unpunished in my favorite cartoon show $(\mathrm{n}=106)$. Only 11 participants Strongly Agreed/Agreed with the item Violence goes unpunished in my favorite cartoon show (10.38\%); about one-third of participants (32) were Neutral about this item (30.19\%); and more than half of the participants (63) Strongly Disagreed/Disagreed (59.43\%). Kendall's tau-b was determined to have a value of 0.290 with a $p \geq 0.000$. This indicates there was a statistical correlation with the dependent variable The older one gets, the more used to they are seeing violence in cartoons. Participants who Strongly Disagree/Disagree with this item will have linear concordance in their answers with relation to the dependent variable. Since the value for Kendall's tau-b was relatively low, 0.290 , the relationship between the dependent variable and this item was weak.

The chi-square value for this item was 30.696 with a $p \geq 0.015$ and 16 DF. The chi-square value at the $95^{\text {th }}$ percentile with 16 DF was 26.30. Since the computed chi-square value was greater than the chi-square value in the table of distribution, the research hypothesis, adolescents' exposure to violent content by viewing it in animation had effects on the beliefs and perceptions of adolescents' abilities to learn aggressive attitudes and behaviors, was rejected. 


\section{Relationship Between Beliefs \& Perceptions and Exposure to Violence on The Simpsons}

To what extent are adolescents' beliefs and perceptions affected regarding the learning of aggressive attitudes and behaviors through exposure to violence by viewing it in animation in The Simpsons? The purpose of this question was to determine if there is a relationship between participants' beliefs and perceptions and exposure to animated violence in The Simpsons.

By conducting chi-square analysis on the dependent variable After I watch violence on The Simpsons, I become aggressive and two independent variables indicated the presence of some significant relationships. The first independent variable indicating a very significant relationship with the dependent variable was Shortly after I see violence on The Simpsons, I become violent $(n=70)$. More than three-fourths of participants (60) Strongly Disagreed/Disagreed with the item Shortly after I see violence on The Simpsons I become violent (85.71\%); nine participants were Neutral on this item (12.86\%); and one respondent Strongly Agreed/Agreed (1.43\%). Kendall's tau-b was determined to have a value of 0.846 with a $p \geq 0.000$. This indicates there was a statistical correlation with the dependent variable After I watch violence on The Simpsons, I become aggressive. Participants who Strongly Disagree/Disagree with this item will have linear concordance in their answers with relation to the dependent variable. Since the value for Kendall's tau-b was extremely high, 0.846 , the relationship between the dependent variable and this item was very strong.

The chi-square value for this item was 161.034 with a $p \geq 0.000$ and 9 DF. The chi-square value at the $95^{\text {th }}$ percentile with 9 DF was 16.92. Since the computed chi-square value was greater than the chi-square value in the table of distribution, the research hypothesis, adolescents' exposure to violent content by viewing it in animation in The Simpsons had effects on the beliefs and perceptions of adolescents' abilities to learn aggressive attitudes and behaviors, was rejected.

The final independent variable with significant relationship with the dependent variable was Violence on The Simpsons is realistic $(n=70)$. (See Table 2) More than three-fourths of participants (54) Strongly Disagreed/Disagreed with the item Violence on The Simpsons is realistic (77.14\%); 12 participants were Neutral on this item (17.14\%); and four participants Strongly Agreed/Agreed (5.41\%). Kendall's tau-b was determined to have a value of 0.387 with a $\mathrm{p} \geq 0.000$. This indicates there was a statistical correlation with the dependent variable After I watch violence on The Simpsons, I become aggressive. Participants who Strongly Disagree/Disagree with this item will have linear concordance in their answers with relation to the dependent variable. Since the value for Kendall's tau-b was moderate, 0.387 , the relationship between the dependent variable and this item was slightly strong. 
Table 2

Comparison of after I watch violence on The Simpsons I become aggressive and violence on The Simpsons is realistic Cross Tabulation.

\begin{tabular}{|c|c|c|c|c|c|c|}
\hline \multirow{6}{*}{$\begin{array}{l}\text { Simpsons } \\
\text { Aggressive }\end{array}$} & \multicolumn{6}{|c|}{ Simpsons Realistic } \\
\hline & & $\begin{array}{l}\text { Strongly } \\
\text { Disagree }\end{array}$ & Disagree & Neutral & Agree & $\begin{array}{c}\text { Strongly } \\
\text { Agree }\end{array}$ \\
\hline & $\begin{array}{l}\text { Strongly } \\
\text { Disagree }\end{array}$ & $41.43 \%$ & $17.14 \%$ & $7.14 \%$ & $1.43 \%$ & $0 \%$ \\
\hline & Disagree & $2.86 \%$ & $7.14 \%$ & $2.86 \%$ & $1.43 \%$ & $0 \%$ \\
\hline & Neutral & $4.29 \%$ & $4.29 \%$ & $5.71 \%$ & $0 \%$ & $2.86 \%$ \\
\hline & Agree & $0 \%$ & $0 \%$ & $1.43 \%$ & $0 \%$ & $0 \%$ \\
\hline
\end{tabular}

Note: $\chi 2=26.264 \quad \mathrm{DF}=12 \mathrm{p} \geq .010$ Kendal's tau- $\mathrm{b}=.387 \mathrm{p} \geq .000$

The chi-square value for this item was 26.264 with a $p \geq 0.010$ and 12 DF. The chi-square value at the $95^{\text {th }}$ percentile with 12 DF was 21.03 . Since the computed chi-square value was greater than the chi-square value in the table of distribution, the research hypothesis, adolescents' exposure to violent content by viewing it in animation in The Simpsons had effects on the beliefs and perceptions of adolescents' abilities to learn aggressive attitudes and behaviors, was rejected.

\section{Perceptions of Television Violence as an Unrealistic View of the Real World} Do adolescents perceive that violence portrayed on television produces an unrealistic view of violence in the real world? The purpose of this question is to determine participants' perceptions of violence in the real world. By conducting chi-square analysis on the dependent variable The older I get, the more I get used to seeing violence in real-life and two independent variables indicated the presence of some significant relationships.

The first independent variable indicating a relationship with the dependent variable was When I get mad at someone, I use violence to solve a problem $(\mathrm{n}=213)$. Only seven participants Strongly Agreed/Agreed with the item When I get mad at someone, I use violence to solve a problem (3.29\%); 29 participants were Neutral about this item (13.62\%); and more than threefourths of the participants (177) participants Strongly Disagreed/Disagreed (83.09\%). Kendall's tau-b was determined to have a value of 0.266 with $a p \geq 0.000$. This indicates there was a statistical correlation with the dependent variable The older I get, the more I get used to seeing violence in real-life. Participants who Strongly Disagree/Disagree with this item will have linear concordance in their answers with relation to the dependent variable. Since the value for Kendall's tau-b was relatively low, 0.266 , the relationship between the dependent variable and this item was weak.

The chi-square value for this item was 51.038 with a $p \geq 0.000$ and 16 DF. The chi-square value at the $95^{\text {th }}$ percentile with 16 DF was 26.30 . Since the computed chi-square value was greater than the chi-square value in the table of distribution, the research hypothesis, adolescents' beliefs and perceptions of the violence portrayed on television produces an unrealistic view of violence in the real world, was rejected.

The final independent variable indicating a significant relationship with the dependent variable was I have used aggressive actions seen on television as a way to deal with some of my problems $(\mathrm{n}=216)$. Only eight participants Strongly Agreed/Agreed with the item I have used 
aggressive actions seen on television as a way to deal with some of my problems (3.7\%); 24 participants were Neutral on this item (11.11\%); and more than three-fourths of the participants (184) Strongly Disagreed/Disagreed (85.19\%). Kendall's tau-b was determined to have a value of 0.217 with a $p \geq 0.000$. This indicates there was a statistical correlation with the dependent variable The older I get, the more I get used to seeing violence in real-life. Participants who Strongly Disagree/Disagree with this item will have linear concordance in their answers with relation to the dependent variable. Since the value for Kendall's tau-b was low, 0.217 , the relationship between the dependent variable and this item was weak.

The chi-square value for this item was 52.270 with a $p \geq 0.000$ and 16 DF. The chi-square value at the $95^{\text {th }}$ percentile with 16 DF was 26.30. Since the computed chi-square value was greater than the chi-square value in the table of distribution, the research hypothesis, adolescents' beliefs and perceptions of the violence portrayed on television produces an unrealistic view of violence in the real world, was rejected.

\section{Perceptions of Animated Television Violence as an Unrealistic View of the Real World}

Do adolescents perceive that the violence portrayed in animation/ The Simpsons produces an unrealistic view of violence in the real world? The purpose of this question was to determine participants' beliefs and perceptions on their view of violence in the real world. By conducting chi-square analysis on the dependent variable Violence on The Simpsons is realistic, two independent variables indicated the presence of some significant relationships.

By conducting chi-square analysis an independent variable indicating a significant relationship with the dependent variable was After I watch violence on The Simpsons, I become aggressive $(\mathrm{n}=70)$. More than three-fourths of participants (57) Strongly Disagreed/Disagreed with the item After I watch violence on The Simpsons, I become aggressive (81.43\%); 12 participants were Neutral about this item (17.14\%); and one participant Strongly Agreed/Agreed (1.43\%). Kendall's tau-b was determined to have a value of 0.387 with a $p \geq 0.000$. This indicates there was a statistical correlation with the dependent variable Violence on The Simpsons is realistic. Participants who Strongly Disagree/Disagree with this item will have linear concordance in their answers with relation to the dependent variable. Since the value for Kendall's tau-b was moderate, 0.387 , the relationship between the dependent variable and this item was slightly strong.

The chi-square value for this item was 26.264 with a $p \geq 0.010$ and 12 DF. The chi-square value at the $95^{\text {th }}$ percentile with $12 \mathrm{DF}$ was 21.03 . Since the computed chi-square value was greater than the chi-square value in the table of distribution, the research hypothesis, adolescents' beliefs and perceptions of the violence portrayed in animation/ The Simpsons produces an unrealistic view of violence in the real world, was rejected.

The final independent variable indicating a significant relationship with the dependent variable was Shortly after I see violence on The Simpsons I become violent $(n=71)$. (See Table 3) More than three-fourths of participants (61) Strongly Disagreed/Disagreed with the item Shortly after I see violence on The Simpsons I become violent (85.92\%); nine participants were Neutral on this item (12.68\%); and one participant Strongly Agreed/Agreed (1.41\%). Kendall's tau-b was determined to have a value of 0.455 with a $p \geq 0.000$. This indicates there was a statistical correlation with the dependent variable Violence on The Simpsons is realistic. Participants who Strongly Disagree/Disagree with this item will have linear concordance in their answers with 
relation to the dependent variable. Since the value for Kendall's tau-b was moderately high, 0.455 , the relationship between the dependent variable and this item was strong.

\section{Table 3}

Comparison of violence on The Simpsons is realistic and shortly after I see violence on The Simpsons I become violent Cross Tabulation.

\begin{tabular}{|l|c|c|c|c|c|c|}
\hline \multirow{4}{*}{} & \multicolumn{9}{|c|}{ Simpsons Violent } & \\
\cline { 2 - 7 } & & $\begin{array}{c}\text { Strongly } \\
\text { Disagree }\end{array}$ & Disagree & & Neutral & Agree \\
\cline { 2 - 7 } $\begin{array}{l}\text { Simpsons } \\
\text { Realistic }\end{array}$ & $\begin{array}{c}\text { Strongly } \\
\text { Disagree }\end{array}$ & $46.48 \%$ & $0 \%$ & & $2.82 \%$ & $0 \%$ \\
\cline { 2 - 7 } & Disagree & $18.31 \%$ & $8.45 \%$ & & $1.41 \%$ & $0 \%$ \\
\cline { 2 - 7 } & Neutral & $8.45 \%$ & $1.41 \%$ & & $5.63 \%$ & $1.41 \%$ \\
\cline { 2 - 7 } & Agree & $1.41 \%$ & $1.41 \%$ & & $0 \%$ & $0 \%$ \\
\cline { 2 - 7 } & $\begin{array}{c}\text { Strongly } \\
\text { Agree }\end{array}$ & $0 \%$ & $0 \%$ & & $2.82 \%$ & $0 \%$ \\
\hline
\end{tabular}

Note: $\chi 2=41.351 \quad \mathrm{DF}=12 \mathrm{p} \geq .000 \quad$ Kendal's tau- $\mathrm{b}=.455 \quad \mathrm{p} \geq .000$

The chi-square value for this item was 41.351 with a $p \geq 0.000$ and $12 \mathrm{DF}$. The chi-square value at the $95^{\text {th }}$ percentile with 12 DF was 21.03 . Since the computed chi-square value was greater than the chi-square value in the table of distribution, the research hypothesis, adolescents' beliefs and perceptions of the violence portrayed in animation/ The Simpsons produces an unrealistic view of violence in the real world, was rejected.

\section{Perceptions of Violence Justification on The Simpsons}

Do adolescents perceive that the violence portrayed on The Simpsons is justified? The purpose of this question was to determine participants' beliefs and perceptions on the justification of violence on The Simpsons. By conducting chi-square analysis on the dependent variable $I$ think violence is justified on The Simpsons, an independent variable indicated the presence of some significant relationships.

The independent variable indicating a significant relationship with the dependent variable was $I$ think it is acceptable for my favorite character on The Simpsons to use violence to solve his/her problems $(n=69)$. More than half of the participants (41) Strongly Disagreed/ Disagreed with the item I think it is acceptable for my favorite character on The Simpsons to use violence to solve his/her problems (59.42\%); about one-third of the participants (22) were Neutral on this item (31.88\%); and six participants Strongly Agreed/Agreed (8.69\%). Kendall's tau-b was determined to have a value of 0.594 with a $p \geq 0.000$. This indicates there was a statistical correlation with the dependent variable I think violence is justified on The Simpsons.

Participants who Strongly Disagree/Disagree with this item will have linear concordance in their answers with relation to the dependent variable. Since the value for Kendall's tau-b was high, 0.594, the relationship between the dependent variable and this item was strong.

The chi-square value for this item was 55.210 with a $p \geq 0.000$ and 16 DF. The chi-square value at the $95^{\text {th }}$ percentile with 16 DF was 26.30. Since the computed chi-square value was greater than the chi-square value in the table of distribution, the research hypothesis, adolescents' perceive the violence portrayed in The Simpsons to be justified, was rejected. 


\section{Summary and Implications for Practice}

The findings from this study provide valuable information regarding adolescents and their perceptions of animation violence as an indication of aggressive attitudes of behaviors. It is important to emphasize the main findings of this study regarding participants' beliefs and perceptions of adolescents on whether or not viewing violence on television contributes to an increase in adolescents' abilities to learn aggressive attitudes and behaviors, as well as the effects humor and satire used on the animated television series The Simpsons. In addition, this study has provided insight into participants' beliefs and perceptions about television violence, unrealistic views of violence in the real world, and the justification of violence.

Results found their exposure to violent content by viewing it on television, animation and The Simpsons does not have effects on the beliefs and perceptions of adolescents' abilities to learn aggressive attitudes and behaviors. Results also found that adolescents' beliefs and perceptions of the violence portrayed on television, animation and The Simpsons do not produce an unrealistic view of violence in the real world. The study has implications for understanding adolescents' beliefs and perceptions of television violence, animation violence and violence on The Simpsons. Recommendations for future research include exploring the effects of school environment on adolescents' beliefs and perceptions of television violence, animation violence and violence on The Simpsons.

In order to properly curb adolescent violence, the behaviors associated with violence need to be identified before they can escalate. These warning signs are: intense anger, frequent loss of temper or blow-ups, extreme irritability, extreme impulsiveness, and becoming easily frustrated (American Academy of Child and Adolescent Psychiatry, 2004). Parents and teachers have the ability to identify these behaviors early on. If a parent or other adult becomes concerned about their child's behaviors, they should arrange for a comprehensive evaluation by a qualified mental health professional.

Physicians should make parents and schools knowledgeable about media. They should understand the risks of exposure to violence and teach adolescents how to interpret what they see on television and in the movies, including the intent and content of commercials. By doing so, adolescents may be increasingly able to discern which media messages are suitable.

\section{References}

American Academy of Child and Adolescent Psychiatry. (2004). Understanding violent behavior in children and adolescents. Retrieved April 3, 2004, from www.aacap.org/publications/factsfam/behavior.htm 2004

Atkin, C.K. (1983). Effects of realistic TV violence vs. fictional violence on aggression. Journalism Quarterly, 60, 615-621.

Bandolier (2005). Cross-sectional study. Retrieved March 4, 2004, from http://www.jr2.ox.ac.uk/bandolier/booth/glossary/csect.html

Bandura, A. (1965). Influence of models' reinforcement contingencies on the acquisition of imitative response. Journal of Personality and Social Psychology, 1, 589-595. 
Bandura, A. (1994). Social cognitive theory of mass communication. In J. Bryant \& D. Zillmann (Eds.), Media effects: Advances in theory and research (pp. 61-90). Hillsdale, NJ: Lawrence Erlbaum.

Baron, R.A. (1978). The influence of hostile and non-hostile humor upon physical aggression. Personality and Social Psychology Bulletin, 4, 77-80.

Berkowitz, L. (1970). Aggressive humor as a stimulus to aggressive responses. Journal of Personality and Social Psychology, 2, 359-369.

Berkowitz, L. (1990). On the formation and regulation of anger and aggression: A cognitive neoassociationistic analysis. American Psychologist, 45, 494-503.

Congressional Public Health Summit. (2000). Joint statement on the impact of entertainment violence on children. Retrieved February 17, 2005, from

www.aap.org/advocacy/releases/jstmtevc.htm

Dictionary.com. (2005). Retrieved June 2, 2005 from

http://dictionary.reference.com/search?q=media

DuRant, R.H., Treiber, F., Goodman, E., Woods, E.R. (1996) Intentions to use violence among young adolescents. Pediatrics.

Geen, R.G. (1981). Behavioral and physiological reactions to observed violence: Effects of prior exposure to aggressive stimuli. Journal of Personality \& Social Psychology, 40, 868-875.

Gunter, B., \& Furnham, A. (1984). Perceptions of television violence: Effects of programme genre and type of violence on viewers' judgments of violent portrayals. British Journal of Social Psychology, 23, 155-164.

Hapkiewicz, W.G. (1979). Children's reactions to cartoon violence. Journal of Personality \& Social Psychology, 8, 1, 30-35.

Kaiser Family Foundation. (2010). Generation M2: Media in the lives of 8-18 year olds. Menlo Park: CA: Kaiser Family Foundation.

Kinderstart. (2000). TV \& elementary kids. Retrieved January 14, 2005, from http://www.kinderstart.com/frame for links.php?redirect=http://www.limitv.org/kids.htm

Mental Health. (2004). What you need to know about youth violence prevention. Retrieved February 2, 2005, from www.mentalhealth.org/publications/allpubs/SVP-0054/pathways.asp

National 4-H Web. (2005). For youth by youth. Retrieved June 7, 2005 from http://www.4-h.org/

National Cable Television Association. (1996). National Television Violence Study. Retrieved June 7, 2005 from http://www.ncta.com/

Nielson Media Research. (1995). Retrieved March 18, 2004, from www.babybag.com/articles/amaviol.htm 
Rich, M. (2000). Violent Video Games Testimony. Retrieved February 15, 2004, from http://216.239.53.104/search?q=cache:N94j ugDRloJ:www.aap.org/advocacy/richvideogamevi olence.pdf+violent+media, +violent+behavior, +adolescents\&hl=en\&ie=UTF-8

Roth, J., \& Brooks-Gunn, J. (2000). What do adolescents need for healthy development? Implications for youth policy. Social Policy Report, 14, 3-19.

Simpson Crazy. (2001). Retrieved March 19, 2004, from http://www.simpsoncrazy.com/information/articles/values.shtml

Social Research Methods. (2002). Unit of analysis. Retrieved June 7, 2005, from http://www.socialresearchmethods.net/kb/unitanal.htm

Thomas, M.H., \& Drabman, R.S. (1975). Effects of viewing real versus fantasy violence upon interpersonal aggression. Journal of Research in Personality, 8, 155-160.

Thomas, M.H., Horton, R.W., Liipincott, E.C., \& Drabman, R.S. (1977). Desensitization to portrayals of real-life aggression as a function of exposure to television violence. Journal of Personality \& Social Psychology, 35, 450-458.

U.S. Department of Health and Human Services. (2001). Youth violence: a report of the surgeon general. Retrieved April 2, 2005, from www.surgeongeneral.gov/library/youthviolence/report.html

Wilson, B.J., Kunkel, D., Linz, d., Potter, W.J., Donnerstein, E., Smith, S.L., Blumenthal, E., \& Gray, T. (1997). Violence in television programming overall: University of California Santa Barbara study. In National television violence study (Vol. 1, pp. 3-268). Thousand Oaks, CA: Sage.

Wilson, B.J., Smith, S.L., Potter, W.J., Kunkel, D., Linz, D., Colvin, C. \& Donnerstein, E.I. 2002). Violence in children's television programming: Assessing the risks. Journal of Communication. 52(1), 5-35.

Wotring, C.E., \& Greenberg, B.S. (1973). Experiments in televised violence and verbal aggression: Two exploratory studies. Journal of Communication, 23, 446-460.

(c) Copyright of Journal of Youth Development Bridging Research and Practice. Content may not be copied or emailed to multiple sites or posted to a listserv without copyright holder's express written permission. Contact Editor at: patricia.dawson@oregonstate.edu for details. However, users may print, download or email articles for individual use.

ISSN 2325-4009 (Print); ISSN 2325-4017 (Online) 